\title{
THE
}

\section{Selected Organohalogenated Flame Retardants in Egyptian Indoor and Outdoor Environments: Levels, Sources and Implications for Human Exposure}

\author{
Mohammed A. Khairy \\ Rainer Lohmann \\ University of Rhode Island, rlohmann@uri.edu
}

Follow this and additional works at: https://digitalcommons.uri.edu/gsofacpubs

The University of Rhode Island Faculty have made this article openly available.

Please let us know how Open Access to this research benefits you.

This is a pre-publication author manuscript of the final, published article.

Terms of Use

This article is made available under the terms and conditions applicable towards Open Access Policy Articles, as set forth in our Terms of Use.

\section{Citation/Publisher Attribution}

Khairy, M., \& Lohmann, R. (2018). Selected organohalogenated flame retardants in Egyptian indoor and outdoor environments: Levels, sources and implications for human exposure. Science of The Total Environment, 633, 1536-1548. doi:10.1016/j.scitotenv.2018.03.243

This Article is brought to you for free and open access by the Graduate School of Oceanography at DigitalCommons@URI. It has been accepted for inclusion in Graduate School of Oceanography Faculty Publications by an authorized administrator of DigitalCommons@URI. For more information, please contact digitalcommons-group@uri.edu. 
$9 \quad *$ Corresponding author. E-mail address: mohammed_khairy77@yahoo.com

\section{Selected Organohalogenated Flame Retardants in Egyptian Indoor and Outdoor} Environments: Levels, Sources and Implications for Human Exposure Mohammed A. Khairy ${ }^{\mathrm{a}, \mathrm{b}^{*},}$, Rainer Lohmann ${ }^{\mathrm{a}}$

${ }^{a}$ Graduate School of Oceanography, University of Rhode Island, Narragansett, Rhode Island 02882 USA

${ }^{b}$ Department of Environmental Sciences, Faculty of Science, Alexandria University, 21511 Moharam Bek, Alexandria, Egypt

Phone: 402-444-7596 


\section{$31 \quad$ Highlights}

32

33

34

35

36

37

38

39

40

41

42

43

44

45

46

47

48

49

50

51

52

53

54

55

56

57

58

59

- Indoor levels of flame retardants were significantly higher than outdoors.

- PBDEs>NFRs and BDE-47, 99, HBB, BTBPE and DDC-CO were the most abundant analytes.

- Significant log-linear $\mathrm{K}_{\text {dust-air- }} \mathrm{K}_{\mathrm{OA}}$ relationships indicated an equilibrium state.

- Low adverse health effects from inhalation/ingestion/dermal exposure pathways.

7

8

9

0

1

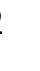

3

4

5

4

8

9

50

1

2

3

4

5

6

7

8

59




\section{Abstract}

61 There is scant information on the presence of the polybrominated diphenyl ethers (PBDEs) and 62 other alternative flame-retardants (NFRs) in Africa. Hence, to investigate their levels, sources, 63 and human exposure scenarios, elevated fine dust (EFD) samples from apartments $(\mathrm{n}=12)$, 64 working places $(n=9)$ and cars $(n=12)$, floor dust $(F D)$ samples $(n=5)$ and outdoor dust 65 samples $(\mathrm{n}=21)$ were collected from Alexandria, Egypt during 2014. Gaseous concentrations

66

67 were estimated using low density polyethylene sheets $(n=33$ and 21 for indoor and outdoor sites respectively). Indoor gaseous and dust PBDE $\left(7.0-300 \mathrm{pg} / \mathrm{m}^{3} ; 4.0-770 \mathrm{ng} / \mathrm{g}\right)$, and NFR $(0.40-$ $\left.48 \mathrm{pg} / \mathrm{m}^{3} ; 0.50-8.5 \mathrm{ng} / \mathrm{g}\right)$ concentrations were significantly higher $(\mathrm{p}=0.004-0.02)$ than outdoor concentrations (PBDEs: $3.0-41 \mathrm{pg} / \mathrm{m}^{3}, 1.5-195 \mathrm{ng} / \mathrm{g}$; NFRs: $0.20-13 \mathrm{pg} / \mathrm{m}^{3}, 0.50-$ $4.0 \mathrm{ng} / \mathrm{g})$. Median PBDE concentration in cars $(210 \mathrm{ng} / \mathrm{g})$ was higher in apartments and working places (129 and $131 \mathrm{ng} / \mathrm{g}$ respectively). PBDE concentrations in FD were 7.0 - 14-folds lower than EFD concentrations. Outdoor PBDE concentrations were significantly higher $(\mathrm{p}<0.01)$ at residential - industrial places with older buildings. All samples were dominated by BDE-47 and 99. HBB, BTBPE and DDC-CO were the most abundant NFRs in EFD samples. Profiles of PBDE and NFR in FD closely matched those of outdoor dust, indicating a possible carryover from the outdoor environment. Although factors such as number of electronics, construction year and floor type significantly correlated with the majority of PBDE congeners and some NFRs in apartments and working places, sources were not clearly identified for NFRs. Significant loglinear relationships were obtained between theoretical and calculated dust-air partitioning coefficients for all samples indicating an equilibrium state between dust and vapor. Low possibility of occurrence of adverse health effects was concluded, with the inhalation pathway (for adults) and dust ingestion (for children) acting as the most important exposure routes. 
83 Keywords: PBDEs, NFRs, LDPE, Indoor, Outdoor, dust, health effects

84

85

86

87

88

89

90

91

92

93

94

95

96

97

98

99

100

101

102

103

104

105

\section{Introduction}

Polybrominated diphenyl ethers (PBDEs) have been widely used worldwide since the 1970s (de Wit, 2002) to reduce fire risks. Although their production has phased out, they still exist in products and thus become released into the environment (Abbasi et al., 2015). Due to the phase out of PBDEs (Abbasi et al., 2015), alternative halogenated (NFRs) and organophosphate flame retardants (OPFRs) are now widely used in consumer products as substitutes (McDonough et al., 2016). PBDEs and NHRs can accumulate in humans (Leonetti et al., 2016; Liu et al., 2015) and thus numerous adverse health effects could occur ( Costa and Giordano, 2007; Nakari and Huhtala, 2010).

PBDEs and NFRs have been detected in the indoor air (Al-Omran and Harrad, 2016; Cao et al., 2014; Fromme et al., 2014; Hassan and Shoeib, 2015; Kademoglou et al., 2017; Shoeib et al., 2012) and outdoor air and dust worldwide (Kurt-Karakus et al., 2017; Mahmood et al., 2015; McDonough et al., 2016; Salamova et al., 2014). The indoor environment with expected higher concentrations and longer exposure periods received special attention (Wilford et al., 2004).

The majority of the indoor studies concentrated on the floor dust (FD) (Ali et al., 2013; Cequier et al., 2014; Dodson et al., 2012; Fromme et al., 2014; Hassan and Shoeib, 2015; Kurt-Karakus et al., 2017; Shoeib et al., 2012). Few studies investigated (elevated) fine dust collected $\sim 1$ meter above the ground (Al-Omran and Harrad, 2016; Newton et al., 2015; Thuresson et al., 2012). In countries with high ambient particulate levels and dust content like Egypt, we hypothesized that floor dust will not properly represent the indoor environment due to the possible carryover of dust and dirt by the shoes from outdoors. However, although dust collected 
106 from elevated surfaces would be a better representative of exposure for adults, children are more 107 exposed to the floor dust.

108 Low density polyethylene passive samplers (LDPE) have been widely used for monitoring 109 hydrophobic organic compounds (HOCs) in the atmosphere (Bartkow et al., 2004; Kennedy et 110 al., 2007; Khairy and Lohmann, 2014, 2013; McDonough et al., 2016). However, they have been 111 rarely used to monitor indoor air pollution. HOCs accumulate in passive air samplers via 112 diffusion and absorption into the sampler matrix, with a high enrichment in LDPE (Sacks and 113 Lohmann, 2011) thus offering lower detection limits compared to conventional samplers. 114 Accordingly, LPDE can be used as a very useful tool in screening level risk assessment studies. Although PBDEs and NFRs were extensively investigated in the indoor dust and the ambient air

117 worldwide, only few studies investigated their concentrations in the indoor dust (Abdallah and 118 Covaci, 2014; Hassan and Shoeib, 2015) and ambient air (Arinaitwe et al., 2014; Pozo et al., 119 2009) collected from Africa. Additionally, none of the studies investigated their levels in the 120 elevated fine dust (EFD), outdoor dust and/or their gaseous levels in the indoor and outdoor 121 environments.

122 In the current study, we studied the levels of PBDEs and NFRs in the indoor and outdoor 123 environments of Alexandria, Egypt. Vapor phase (using LDPE), in- and outdoor dust were 124 collected to: i) determine concentrations, profiles and sources of PBDEs and NFRs in the indoor 125 and outdoor air (gas phase + dust), ii) compare their concentrations among the different indoor 126 microenvironments, and between floor dust and elevated fine dust, iii) assess the link between 127 outdoor dust and indoor contamination, and iv) estimate the human intakes via inhalation and 128 dust ingestion for adults and toddlers. To our knowledge, this is the first comprehensive study to 
measure PBDEs and NFRs in the indoor and outdoor environments, and to utilize LDPE as an indoor passive sampler.

\section{Materials and methods}

Detailed descriptions of the study area, LDPE passive sampling, extraction, cleanup, instrumental analysis, and estimation of the vapor phase concentrations from LDPE are provided in Appendix A, and are briefly summarized below.

\subsection{Sampling}

Indoor and outdoor samples were collected from Alexandria, Egypt (Figure A1) during the late autumn - winter (minimum ventilation effect) of 2014 (November - December). EFD was collected $1 \mathrm{~m}$ above the floor from homes $(\mathrm{n}=12)$ and working places $(\mathrm{n}=9)$ using an Electrolux JetMaxx Bag Canister Vacuum cleaner (Model EL4042A). Dust was collected in cellulose thimbles fitted between the crevice tool and the vacuum tube. The thimble was secured with a stainless-steel ring. At each sampled homes, dust was collected from the living area including the living room, dining room and the bedrooms, where people spend most of their indoor times (greatest exposure likelihood), and many products exist that may be sources of the target flame retardants. Prior to sampling, participants were asked not to vacuum or ventilate their places for a week. The crevice tool was passed on all the available surfaces in the rooms. After each of the 6 dust collection events at each location, the thimble was carefully removed, wrapped in a pre-combusted aluminum foil, sealed in plastic zip bag, and stored at $-4{ }^{\circ} \mathrm{C}$. After the final sampling event, thimbles were stored at $-20{ }^{\circ} \mathrm{C}$ until analysis. Similarly, EFD from cars $(n=12)$ were obtained from all available surfaces except the floor (to prevent the effect of carryover from street dust). Participants were asked not to vacuum their vehicles at least two 
153 weeks before sampling and until the end of the sampling event (45 days). 15 indoor samples

154 (other than what was analyzed in the current study) were excluded from further consideration

155 because volunteers failed to follow our pre-sampling guidelines (see Appendix A).

156

157

158

159

160

161

162

163

164

165

166

167

168

169

170

171

172

173

174 the cars, and 38 at working places (total = 108 samples). For the extraction/analysis step, all the

175 LDPE sheets deployed at the different rooms within an apartment or working place were

176 combined and analyzed together $(\mathrm{n}=12,9$ and 12 for apartments, working places and cars

177 respectively $\mathrm{x}$ duplicates). 


\subsection{Extraction, cleanup and instrumental analysis}

179 Dust samples (indoor and outdoor) were sieved through a 3-inch, 100 mesh $(150 \mu \mathrm{m})$ stainless steel sieve (Dodson et al., 2012), and $\sim 0.5$ g dry weight were sonicated with n-hexane/acetone

$181(1: 1, \mathrm{v}: \mathrm{v})$ after spiking with surrogate standards $\left(10 \mu \mathrm{L}\right.$ of a $2.0 \mathrm{ng} / \mu \mathrm{L}$ solution of ${ }^{13} \mathrm{C}_{12} \mathrm{BDE}-28$, 182 47, 99, 153 and 183 in nonane), purified and fractionated (fraction1 containing target analytes 183 and fraction 2 containing organophosphate flame retardants, which is not discussed in the current 184 manuscript) over silica gel and concentrated to a final volume of $\sim 25 \mu \mathrm{L}$ after the addition of the 185 injection standards. LDPE samplers were spiked with surrogate standards and cold extracted 186 twice with methylene chloride and n-hexane for $24 \mathrm{~h}$ each with no further cleanup.

187

Extracts were analyzed for 12 PBDE congeners (BDE-2, 8, 15, 28, 30, 47, 49, 99, 100, 153, 154 and 183) and 9 NFRs [tetrabromo- $p$-xylene (TBX), pentabromobenzene (PBB), pentabromotoluene (PBT), pentabromoethylbenzene (PBEB), hexabromobenzene (HBB), 191 hexachlorocyclo-pentadienyl-dibromocyclooctane (DBHCTD), 1,2-bis (2,4,6-tribromophenoxy) 192 ethane (BTBPE), and anti- and syn-isomers of Dechlorane Plus (a-DDC-CO and s-DDC-CO)] on 193 an Agilent 6890N gas chromatograph coupled to a Waters Quattro Micro mass spectrometer 194 (GCMS/MS) in electron ionization mode (EI, $70 \mathrm{eV})$ using multiple reaction monitoring (MRM).

\subsection{Quality assurance}

197

Field blanks (Table A2), matrix spikes, and duplicate samples were included with each sample batch. Field blanks were composed of anhydrous sodium sulphate $(3 \mathrm{~g})$ contained in either a

200 thimble, dust bag or a glass jar (based on the type of the sample). To prevent cross contamination 201 between the sampling locations, cleaning of the vacuum cleaner was performed before and after 202 ach sampling event (at each location) by using a detergent, warm water, methanol and air-drying. 
Matrix spikes were prepared by spiking ground sea sand $(1 \mathrm{~g})$ contained in a thimble, dust bag or 204 glass jar with $15 \mu \mathrm{L}$ of a solution composed of all the target analytes at a concentration of 2.0 $205 \mathrm{ng} / \mu \mathrm{L}$ in nonane, and performing the same analytical steps as the samples. All the LDPE were 206 deployed and analyzed in duplicates. For the dust samples, $30 \%$ of the total number of samples 207 were analyzed in duplicates. Instrumental calibrations were checked by injection of the 208 continuing calibration solution. The GC/MSMS calibration was verified before, during, and after 209 each analytical sequence. Three calibration standards were continuously injected every 10 dust 210 samples and 15 LDPE samples and the calibration check was maintained within $\pm 15 \%$ for all 211 analytes of interest. When an analyte was not detected, the noise was quantitated for the limit of 212 detection (LOD) calculations. LODs were determined in the different matrices as the upper limit 213 of the $95 \%$ confidence interval for the field blanks (Table A3). We used $1 / 2$ the LOD for 214 concentrations that were below the detection limit. Recoveries of the surrogate standards 215 generally ranged from $74-92 \%$ and $71-96 \%$ for the outdoor and indoor LDPE respectively, 63 $216-86 \%$ for the outdoor dust, $64-91 \%$ for the indoor fine dust and $67-96 \%$ for the floor dust.

217 Matrix spikes recoveries ( $\mathrm{n}=5$ for LDPEs and 6 for dust) ranged from $82 \%$ (BDE 2) to $102 \%$ 218 (BDE 154) for the LDPE and from $76 \%$ (BDE-2) to $103 \%$ (BDE-100) for the dust (Table A4) 219 with a relative standard deviation $<20 \%$. Results of the replicate analysis of LDPE and the dust 220 samples indicated that the reproducibility of the analysis ranged from $17.6 \%-25.3 \%$.

\subsection{Human health risk assessment}

223 To calculate the daily exposure doses from inhalation, ingestion and dermal exposure pathways, 224 the following models were used according to the USPEA risk assessment guidelines (Means, 225 1989): 


$$
\mathrm{DD}_{\mathrm{der}}=\frac{\mathrm{C}_{\mathrm{EFD}} \cdot \mathrm{ET} \cdot \mathrm{SA} \cdot \mathrm{AF}_{\mathrm{d}} \cdot \mathrm{ABS}}{\mathrm{BW}} \longrightarrow 3
$$

229 Where,

$230 \mathrm{DD}_{\text {inh, }} \mathrm{DD}_{\text {ing }}$ and $\mathrm{DD}_{\text {der }}$ are the daily dose associated with the inhalation, ingestion and dermal

231 contact (all in $\mathrm{ng} / \mathrm{kg} / \mathrm{d}$ ) from the different micrenvironments, $\mathrm{C}_{\mathrm{g}}=$ the vapor phase concentration

232 of each individual flame retardant $\left(\mathrm{ng} / \mathrm{m}^{3}\right), \mathrm{ET}=$ the exposure time $(\mathrm{h} / \mathrm{d}), \mathrm{InhR}=$ inhalation rate

$233\left(\mathrm{~m}^{3} / \mathrm{d}\right), \mathrm{BW}=$ body weight $(\mathrm{kg}), \mathrm{C}_{\mathrm{EFD}}=$ the concentration of each flame retardant in the elevated

234 fine dust $(\mathrm{ng} / \mathrm{g})$, IngR = ingestion rate $(\mathrm{mg} / \mathrm{d}), \mathrm{ABS}=$ dermal adsorption fraction

235 (dimensionless), $\mathrm{SA}=$ skin surface area exposed $\left(\mathrm{cm}^{2}\right), \mathrm{AF}_{\mathrm{d}}=$ particle-to-skin adherence factor

236 (g/cm²/event).. Note that $\mathrm{DD}_{\text {ing, }} \mathrm{DD}_{\text {ing }}$ and $\mathrm{DD}_{\text {der }}$ are the sum of inhalation, ingestion or dermal

237 contact of vapor phase and elevated fine dust from homes, working places (for adults only), cars

238 and schools.

239

240 The ET was obtained from the answers of the participants in the questionnaire. The average

241 working hours were set as 8.0 and 6.0 hours/day for males and females respectively. For

242 housewives, no working hours were included. For all adults and children, ET in cars was set at 2

243 hours/day. The remainder was the time spent at home. For toddlers, all the time was spent at

244 home. DW was 70, 15 and $12 \mathrm{~kg}$ for adults, children and toddlers respectively (Means, 1989).

245 Selected inhalation rates were 13.3 and $10.9 \mathrm{~m}^{3} /$ day for adults and children (toddlers)

246 respectively (Means, 1989). In the best-case scenario, ingestion rates were set at 0.02 and 0.05

$247 \mathrm{~d} /$ day for adults and children, whereas they were set at $0.05,0.1$ and $0.2 \mathrm{~g} / \mathrm{d}$ for adults, children 
248 and toddlers respectively(Means, 1989). For the dermal exposure pathway, SA used were 8,620

249 and 4,970 $\mathrm{cm}^{2}$ for adults and children(Means, 1989), $\mathrm{AF}_{\mathrm{d}}$ (Means, 1989) was $0.000096 \mathrm{~g} / \mathrm{cm}^{2}$

250 and ABS was 0.03 (Cequier et al., 2014). Available reference dose values (RfD, mg/kg body

251 weight/day) for BDE-47, 99, 153 and HBB were obtained from the Integrated Rias Assessment

252 Information System (IRIS) of the USPEA ( https://www.epa.gov/iris, accessed in 10/01/2017).

253 For BTBPE, RfD was obtained from Ali et al. (2012).

$254 \quad 2.5$. Statistical analysis

255 Analysis of variance (ANOVA) and the student t-test were performed with SigmaPlot 11. Before 256 applying the statistical tests, all numbers were log transformed for normality. Bivariate 257 correlation was performed with IBM SPSS (V 23, USA).

258

259 3. Results and discussion

260 3.1. Indoor concentrations

261 3.1.1. PBDEs: $\sum 12$ PBDE concentrations in the vapor phase ranged from $7.0-300 \mathrm{pg} / \mathrm{m}^{3}, 36-$ $262220 \mathrm{pg} / \mathrm{m}^{3}$ and $13-303 \mathrm{pg} / \mathrm{m}^{3}$ at apartments, working places and cars respectively (Table 1 ). In 263 the EFD, concentrations ranged from $4.10-710,80-540$ and $3.0-770 \mathrm{ng} / \mathrm{g}$ respectively 264 (Table 2). Concentrations of PBDEs (2.0 - $78 \mathrm{ng} / \mathrm{g})$ in floor dust (Table A5) were lower than in 265 EFD by a factor of 7.0 - 14 as was previously observed by Bjorklund et al. (2012) in Sweden. 266 Working places (120 pg/m $\mathrm{m}^{3}$ compared to $66-85 \mathrm{pg} / \mathrm{m}^{3}$ at the other microenvironments) and cars 267 (210 ng/g compared to 129 - $131 \mathrm{ng} / \mathrm{g}$ for the other microenvironments) showed the highest 268 median PBDE concentrations in the vapor phase and EFD samples respectively as was 269 previously observed in the vapor phase samples of Sweden (Thuresson et al., 2012), and dust 270 samples in Cairo, Egypt (Hassan and Shoeib, 2015), and in UK (Stuart et al., 2008). Vapor phase

271 concentrations of BDE-2, 8 and 30 were significantly higher (One-Way Repeated Measures of 
272 ANOVA; $p=0.004-0.025)$ at apartments probably due to limited ventilation at apartments

273 compared to working places and cars.

274 Detected median vapor phase and EFD concentrations of $\sum{ }_{12} \mathrm{PBDE}$ and the individual congeners

275 were generally within the same range or lower than concentrations previously reported

276 worldwide at working places and apartments/houses (Figure 1a,b and Table A6). In contrast,

277 PBDE concentrations in the EFD samples of the cars were much higher than concentrations

278 previously observed in Asia and in Cairo, Egypt (Figure 1c). PBDE concentrations in the FD

279 samples were lower than previously detected concentrations in Europe, Asia and USA (Figure

280 1d) but close to what was previously detected in Cairo, Egypt (Hassan and Shoeib, 2015).

281 However, it should be pointed out that the vapor phase sampling technique used in our study

282 (LDPE passive samplers) is different from the active or passive sampling techniques (using

283 PUFs) used in the other studies and this should be considered when comparing the results.

284 Additionally, differences in the sampling periods, sampled cars (manufacturer, year and

285 mileage), and conditions of the investigated apartments/houses are all significant factors and

286 should be considered in this comparison. Accordingly, we tried to limit our comparisons (Figure

287 1) to studies with very close sampling periods whenever possible.

288

289 BDE-47 and BDE-99 were the dominant congeners in the vapor phase, EFD and FD samples

290 (Figure 2) comprising on average $46-84 \%$ of the total concentrations. In the EFD samples,

291 BDE-99 was the dominant congener compared to BDE-47 in the vapor phase and FD samples.

292 The ratio of BDE-47 to BDE-99 for the vapor phase $(1.0$ - 1.7) and FD samples $(1.3-1.9)$ were

293 slightly higher than values observed for the penta-formulations (0.6 and 1.0, La Guardia et al.,

294 2006), whereas values in the EFD samples were consistent with the penta-formulation (0.4 -

295 0.9), which is probably attributed to the slightly higher volatility of BDE-47 (log vapor pressure 
$296=-3.61 \mathrm{pa})$ compared to BDE-99 (log vapor pressure $=-4.30 \mathrm{pa}$ ) (Yue and Li, 2013). Our

297 findings indicate the possible wide usage of the penta formulation in the imported consumer

298 goods to Alexandria. Additionally, differences in the ratio values between EFD and FD samples

299 suggest a different PBDE sources. BDE-183 (octa- formulation) showed minor contributions $(<$

$30010 \%$ ) (Figure 2) indicating probably a limited usage of the octa-BDE formulation, in-line with

301 results reported for floor dust in Cairo (Hassan and Shoeib, 2015).

302

303 3.1.2. NFRs: Concentrations of NFRs ranged from 0.40 to $47 \mathrm{pg} / \mathrm{m}^{3}, 0.60-10 \mathrm{ng} / \mathrm{g}$ and $0.50-$ $3042.0 \mathrm{ng} / \mathrm{g}$ in the vapor phase, EFD ad floor dust samples respectively (Tables 1, 2 and A5). HBB

305 displayed the highest concentrations (Figure 3) in the vapor phase samples, as was previously 306 observed in Norwegian schools (Cequier et al., 2014). In all the microenvironments, PBEB, PBT 307 and TBX were less abundant than HBB but showed significant contributions in the vapor phase 308 (Figure 3a, c, f). BTBPE, DBHCTD, a-DDC-CO and s-DDC-CO were below LOD in all the 309 samples probably due to their low vapor pressure (vapor pressure $=-5.5$ to $-10.1 \mathrm{~Pa}$ ) 310 (McDonough et al., 2016) and accordingly, their preferential occurrence in the particulate phase 311 as was observed in the current study (Figure 3b, d, f, g). Higher contribution of s-DDC-CO in the 312 EFD of cars and working places was observed in the current study probably due to the usage of 313 the technical DDC-CO as an additive in textile, automotive and in computers (Hassan and 314 Shoeib, 2015).

316 Detected concentrations of NFRs in air and dust of the microenvironments were much lower than 317 concentrations previously recorded worldwide (Table A7). However, EFD median 318 concentrations of HBB (0.25 ng/g), BTBPE (1.0 ng/g), s-DDC-CO (2.0 ng/g) and a-DDC-CO 
$319(0.9 \mathrm{ng} / \mathrm{g})$ in cars of Alexandria were comparable with those observed in Cairo, Egypt $(0.23,1.3$, 3201.5 and 1.0 respectively) (Hassan and Shoeib, 2015). Additionally, median concentrations of

$321 \mathrm{HBB}$ and BTBPE were very close to values reported for the FD samples of Cairo, Egypt (Hassan

322 and Shoeib, 2015), whereas, the median concentrations of s- and a-DDC-CO in Cairo were 3.0

323 and 7.0 fold respectively higher than our reported values. Egypt does not manufacture flame

324 retardants and any detected compounds are due to imported goods. Nevertheless, the lower 325 observed concentrations in the current studies could be the reason of different materials

326 imported, different manufacturing countries, ages and types of materials and electrical equipment

327 used in the different studies, type, age, mileage and manufacturer of the vehicles and/or less strict

328 fire safety standards in Egypt.

329

330

331

332

333

334

335

336

337

338

339

340

341

342

\subsection{Outdoor concentrations}

3.2.1. PBDEs: PBDE concentrations ranged from $3.0-41 \mathrm{pg} / \mathrm{m}^{3}$ and $1.5-200 \mathrm{ng} / \mathrm{g}$ in the vapor phase and dust samples respectively (Table 3). BDE-2 was below the LOD in all the outdoor samples. Vapor phase and dust concentrations of $\sum_{12}$ PBDE, BDE-47, 49, 99, 100, 153 and 154 were significantly higher (t-test, $\mathrm{p}<0.05)$ in the residential - industrial regions. This is probably attributed to the older age of the industrial buildings, ventilation systems and/or the number of items containing PBDEs in the industrial buildings. In all samples (Figures A3, A4), BDE-47 and BDE-99 dominated the profiles of vapor phase and dust samples in the outdoor environment as was previously observed for the indoor microenvironments (Figure 2). However, in the outdoor dust samples, BDE-47 showed higher concentrations that BDE-99 as was observed for the indoor floor dust samples (Figure 2g). Values of BDE-47/BDE-99 ratio $(1.0-2.4)$ at all the locations were slightly higher than values of the penta-BDE formulations (La Guardia et al., 2006), EFD samples (0.4 - 0.9), but consistent with the FD samples (1.3 - 1.9) and the outdoor 
343 gaseous samples $(1.0-1.9)$. The ratio values observed here were probably the result of the faster

344 photodegradation of BDE-99 compared to BDE-47 (Dickhut et al., 2012). BDE- 28, 100 and 153

345 showed also significant contributions in the outdoor dust samples $(8.0-15 \%$ of the total

346 concentrations).

347

348 Detected vapor phase concentrations in the current study were much lower than previously 349 detected concentrations in USA (Batterman et al., 2009), China (Hong et al., 2016) and Turkey 350 (Kurt-Karakus et al., 2017) (Table A6) but higher than values previously observed for air around 351 the lower Great Lakes $\left(0.10-14.5 \mathrm{pg} / \mathrm{m}^{3}\right)(\mathrm{McDonough}$ et al., 2016) and Ottawa, Canada $352\left(<\mathrm{LOD}-4.4 \mathrm{pg} / \mathrm{m}^{3}\right)$ (Wilford et al., 2004).

353

354 355

356

357

358

359

360

361

362

363

364

365

366

3.2.2. NFRs: NFRs concentrations ranged from <LOD $-13 \mathrm{pg} / \mathrm{m}^{3}$ and $0.40-4.0 \mathrm{ng} / \mathrm{g}$ in the outdoor vapor and dust samples respectively (Table 3), with no significant difference between the residential and residential-industrial areas as was previously observed for PBDEs. Concentrations of all the investigated NFRs were much lower than the indoor microenvironments (Table 2), and were also lower than PBDE concentrations (Table 3). Profiles of NFRs in the outdoor environment (Figures A5, A6) were similar to the profiles of NFRs in the vapor phase (dominance of $\mathrm{HBB}, \mathrm{PBB}, \mathrm{PBEB}$ and $\mathrm{PBT}$ ) and dust samples (dominance of BTBPE, s-DDC-Co and a-DDC-CO) of the indoor microenvironments.

Detected concentrations of $\mathrm{PBB}, \mathrm{HBB}, \mathrm{PBT}$ and $\mathrm{PBEB}$ in the current study were much lower than concentrations previously observed in China (Table A7) (Hong et al., 2016; Lin et al., 2013), Stockholm, Sweden (for PBT: <LOD in the current study compared to $0.17 \mathrm{pg} / \mathrm{m}^{3}$ ) (Newton et al., 2015), Istanbul, Turkey (for HBB and BTBPE; Table A7) and Great Lakes (for 
367 BTBPE, DBHCTD, s-DDC-CO and a-DDC-CO) (McDonough et al., 2016). In contrast, the 368 median concentration of HBB in the current study $\left(0.10 \mathrm{pg} / \mathrm{m}^{3}\right)$ was higher than that in Sweden 369 (<LOD), and the range of PBB, HBB and PBEB in the current study was also higher that 370 concentrations observed at the lower Great Lakes. Again, much lower concentrations of NFRs 371 demonstrate that these compounds have not (yet) replaced PBDEs as flame retardants in 372 Alexandria.

373

374

375

376

377

378

379 380 381

382 383 384 385 386 387 388 389 390

\subsection{Indoor vs Outdoor Organohalogenated Flame Retardants}

The lack of correlations between detected vapor concentrations and their subcooled vapor pressures $\left(\mathrm{P}_{\mathrm{L}}, \mathrm{Pa}\right)$ imply that emissions of PBDEs and NFRs were dominated by various source strengths, reactivity but not their volatility. All the gaseous and EFD concentrations of $\sum_{12}$ PBDEs and $\sum$ NFRs in the indoor samples (excluding cars) were significantly higher ( $\mathrm{t}$-test, $\mathrm{t}$ $=2.95-7.13, \mathrm{p}<0.006)$ than the outdoor samples $($ Figure A7). This, in addition to the observed indoor - outdoor pattern variabilities and the between-samples variability in the indoor microenvironments suggests that detected indoor concentrations are mainly from indoor emissions with minimum contribution from the outdoor environment.

In the current study, several findings were observed when we compare indoor and outdoor dust. First, different patterns of PBDE congeners (Figure A7c) were observed in the elevated fine versus floor dust samples (dominance of BDE-47 in FD compared to BDE-99 in the EFD), whereas for the NFRs (Figure A7d) similar patterns were observed in the EFD, FD and outdoor dust samples. Second, greater similarities in concentrations and profiles (Figure A7c, d) of PBDEs and NFRs were observed between floor and outdoor dust (dominance of BDE-47, BTBPE, HBB and s-DDC-CO and similar BDE-47/99 ratios). This finding is unusual 
391 considering the higher expected concentrations in the indoor samples, which is already observed

392 for the gaseous and the elevated fine dust. Additionally, FD concentrations of HBB, BTBPE,

393 DBHCTD and BDE-28 to 183 were more strongly correlated with the outdoor samples $(r=0.74$

$394-0.99, \mathrm{p}<0.05)$ than with elevated fine dust samples $(\mathrm{r}=-0.08-0.90)$, which were not

395 significant $(\mathrm{p}>0.05)$ in most cases. The exception were a-and s-DDC-CO, which displayed

396 stronger correlation to elevated fine dust samples $(r=0.80,0.87$ compared to $r=0.67$ and 0.68

397 for outdoor samples), although they were statistically insignificant $(p>0.05)$. Third, elevated

398 fine dust samples displayed much higher concentrations than floor and outdoor dust and slightly

399 different profiles. Since all samples were sieved, we argue that different sources are responsible

400 for the detected levels of PBDEs and NFRs in the EFD and FD. Floor dust is possibly

401 contaminated by outdoor dust and dirt carried indoors by shoes, whereas this process is of

402 minimum effect for the elevated fine dust (based on our requested pre-sampling and during-

403 sampling ventilation conditions from volunteers).

404

405

3.4. Sources and relations between organohalogenated flame retardants in the samples

$406 \quad 3.4 .1$. Indoor

407 To study the relations between detected flame retardants, a bivariate analysis was performed

408 (correlations). Factors such as year of construction, number of foamed furniture, number of 409 electronics, type of ventilation used and the number of vacuuming per week were included

410 (Table A1). For cars, the make, year, type of seats and the ventilation system were included. All

411 this information was obtained from the questionnaires given to the volunteers. For the indoor air

412 (Table A8) and EFD (Table A9) samples, significant correlation between the tri- through hepta-

413 brominated congeners (BDE- 28 to BDE- 183) was observed indicating possible common

414 sources, the banned penta- and octa- formulations. Although a significant correlation was 
415 observed between all tri- through hepta- brominated congeners, we excluded the possibility of 416 occurrence of debromination and conversion of the higher brominated congener (BDE-183) to

417 lower brominated ones as this finding occurred both in the indoor and outdoor environments (see

418 below). No significant correlations were observed between PBDE congeners in the gaseous and 419 EFD samples and the number of electronics and the number of foamed furniture. However, some 420 within variability was observed at working places. Concentration of PBDE congeners at the car 421 upholstery shop $\left(\sum 12 \mathrm{PBDE}=220 \mathrm{pg} / \mathrm{m}^{3}\right)$ was significantly higher (One-Way Repeated 422 Measures of ANOVA; $\mathrm{p}<0.001)$ than those recorded for the four sampled school offices $\left(\sum 12\right.$ $\left.423 \quad \mathrm{PBDE}=36-120 \mathrm{pg} / \mathrm{m}^{3}\right)$.

424 In the elevated fine dust samples (Table A9), all the PBDE congeners were negatively correlated 425 with the construction year $(\mathrm{r}=0.43-0.62, \mathrm{p}<0.05)$, probably due to the increased dependence 426 on NFRs and OPFRs in recent years. Nevertheless, the majority of the investigated NFRs 427 showed no significant correlations with the construction year. Most of the PBDE congeners 428 showed significant correlations with the floor type (Table A9), where concentrations increased 429 when floors were covered with carpets, probably relating to the use of PBDEs in carpet paddings 430 (Stapleton et al., 2008).

431

432 For NFRs, only PBEB, s- and a-DDC-CO in the EFD samples showed significant correlations (r $433=0.47-0.68, \mathrm{p}<0.05)$ with the number of electronics, probably due to their wide usage in 434 electronics (Sverko et al., 2011). Although BTBPE was used as a replacement for the octa-BDE 435 formulation by the end of 2004 (Kurt-Karakus et al., 2017), no correlation were observed with 436 BDE-183 in the current study. Additionally, median concentrations of BTBPE in EFD of the 437 indoor microenvironments $(0.80-3.0 \mathrm{ng} / \mathrm{g})$ and the outdoor dust $(0.20-0.26 \mathrm{ng} / \mathrm{g})$ were much 438 lower than median concentrations of BDE-183 $(2.2-25 \mathrm{ng} / \mathrm{g}$ and $0.50-2.50 \mathrm{ng} / \mathrm{g}$ respectively), 
439 which may be related to the limited usage of the octa-PBDE formulation in the imported goods

440 in Egypt.

441 The detected concentrations of NFRs in the current study are more affected by the within-site

442 variabilities and thus sources were not clearly identified for this class of flame-retardants. A

443 similar finding was observed in Norway (Cequier et al., 2014).

444

445 As for cars, manufacturer was the key factor for the gaseous organohalogenated flame retardants

446 (Table A14), where vapor phase concentrations of BDE-28 through BDE-154 in the Korean cars

447 were significantly higher (One-Way Repeated Measures of ANOVA; $p<0.004$ ) than the

448 German and Japanese cars sampled here (Table 1). Higher concentrations of the same congeners

449 were also observed in the EFD samples collected from the Korean cars compared to the German

450 and Japanese cars but was statistically insignificant (Table 2). Like the apartments and working

451 places, several significant positive correlations were observed for the different NFRs (Tables

452 A10, A11) indicating common sources. Additionally, the significant correlations between the

453 individual penta- BDE congeners were also observed for the air and dust in cars. HBB in air and

454 dust showed significant positive correlation with the model year $(\mathrm{r}=0.677-0.74, \mathrm{p}<0.05)$,

455 whereas DBHCTD and a-DDC-CO in the dust samples were significantly higher $(\mathrm{r}=0.58-$

$4560.85, \mathrm{p}<0.05)$ in the Korean cars.

457

$458 \quad 3.4 .2$. Outdoor

459 No correlations were found with temperature, wind speed or wind direction (data not shown).

460 Generally, some significant between-analyte correlations were observed for NFRs and for the

461 individual penta-BDE congeners and BDE-183. As we mentioned earlier, industrial activities

462 were only a major source of PBDEs (significantly higher concentrations at the residential - 
463 industrial areas than the residential areas) in the outdoor environment, whereas this pattern was 464 not observed for NFRs.

\subsection{Partitioning of the Organohalogenated Flame Retardants in Air and Dust}

467 To investigate the relationship between the detected concentrations in the dust and air samples, 468 dust-air partitioning coefficients $\left(\mathrm{K}_{\text {dust-air }} ; \mathrm{m}^{3} / \mathrm{g}\right)$ were calculated [concentrations in the dust 469 (ng/g)/air concentrations $\left(\mathrm{ng} / \mathrm{m}^{3}\right)$ ]. For equilibrium conditions, $\mathrm{K}_{\text {dust-air }}$ is expected to be directly 470 proportional to the octanol-air partition coefficient ( $\mathrm{K}_{\mathrm{OA}}$ ) (Cequier et al., 2014; Liagkouridis et 471 al., 2017; Weschler and Nazaroff, 2010). In contrast, if the gaseous fraction was freshly released, 472 or if the flame retardants in the air and dust were emitted from different sources, this relationship 473 would be insignificant. Calculated $\log \mathrm{K}_{\text {dust-air }}$ values were compared with a theoretical $\mathrm{K}_{\text {dust-air }}$ 474 calculated based on $\mathrm{K}_{\mathrm{OA}}$, fraction of organic carbon $\left(f_{\mathrm{OC}}\right)$ and density of dust $\left(\rho_{\text {dust }}, \mathrm{g} / \mathrm{m}^{3}\right)$ as 475 follows:

$477 f_{\mathrm{OC}}$ and $\rho_{\text {dust }}$ were selected as 0.2 and $17 \times 10^{5} \mathrm{~g} / \mathrm{m}^{3}$ (Liagkouridis et al., 2017). Thus, the less 478 volatile flame retardants (higher $\mathrm{K}_{\mathrm{OA}}$ ) will partition preferentially into the dust, thus resulting in 479 higher $\mathrm{K}_{\text {dust-air. }}$

480 In the current study, significant log-linear relationships between the calculated and theoretical $481 \mathrm{~K}_{\text {dust-air }}\left(\mathrm{R}^{2}=0.71-0.82\right.$ for $\mathrm{EFD}$ and $\mathrm{FD}$, and $0.73-0.81$ for the outdoor samples, $\left.\mathrm{p}<0.001\right)$ 482 were observed for elevated fine and floor dust (Figure 4a) and the outdoor samples (Figure 4b). 483 Additionally, slopes of the regression relationships $(b=0.53-0.65)$ were significantly different 484 from zero $(\mathrm{p}<0.001)$ indicating equilibrium distribution of the flame retardants between dust 485 and vapor. Surprisingly, this relationship explained $75 \%$ of the total variability for the elevated 486 fine and floor dust samples, and the slopes were identical $(b=0.60)$ and insignificantly different 
487 from one $(\mathrm{p}<0.001)$. Assuming that floor dust was contaminated by outdoor dust, a stronger 488 relationship for EFD samples is expected. However, this was not observed probably due to the 489 similarity between the profiles of PBDEs and NFRs in the vapor phase samples of the indoor and 490 outdoor environments (Figure 2a, b), the similarities between profiles of NFRs in the EFD and 491 FD samples and/or the possible ongoing emission of flame retardants in the indoor 492 microenvironment, which affected the strength of the relationship.

493

494

495

496

497

498

499

500

501

502

503

504

505

506

507

508

509

510

\subsection{Human Exposure Assessment}

Daily intake of the flame retardants from dust ingestion (based on EFD samples), air inhalation (vapor phase concentrations) and dermal absorption was estimated in the current study for adult males and females (working and housewives), children (age more than 6 years) and toddlers. Calculated daily intakes are given in Table A12. Values generally ranged from $6.8 \times 10^{-6}-0.17$, $2.0 \times 10^{-5}-0.60,7.0 \times 10^{-8}-0.03$ and $1.0 \times 10^{-5}-0.04 \mathrm{ng} / \mathrm{kg}$ body weight/day for the ingestion pathway (best case and worst-case scenarios respectively), inhalation and dermal exposure pathways. Calculated daily dose for the three exposure routes were generally higher for PBDEs than NFRs (Figure 5). Toddlers showed the highest ingestion $\left(2.9 \times 10^{-3}-1.0 \times 10^{-2}\right)$, inhalation $\left(1.4 \times 10^{-3}-5.5 \times 10^{-3}\right)$ and dermal $\left(2.1 \times 10^{-4}-1.3 \times 10^{-3}\right)$ daily dose values compared to the other groups. Ingestion of NFRs was the most important exposure route (higher calculated daily dose values; Table A12) for toddlers, children, adult males and housewives (Figure 5a, 6), and for all the groups with respect to PBDEs. In contrast, inhalation (especially of HBB and TBX) was more important for adult working females. For most of the NFRs, comparable daily dose values (from all exposure routes) were observed for adult males and working females, which were higher than values calculated for housewives (Figure 5a, c, e). This observed pattern is probably attributed to the higher observed concentrations of most of the NFRs at the working 
511 places. In contrast, the pattern was not observed for PBDEs (Figure 5b, d, f). Generally,

512 inhalation pathway was more important for the more volatile flame retardants (TBX, PBB, HBB,

513 PBT, PBEB, BDE-2, 8 and 15), whereas the ingestion pathway was the most important exposure

514 route for BTBPE, DBHCTD, s-DDC-CO, BDE-28, 47, 99, 100 and 153 (Figure 5). Nevertheless,

515 calculated values for BDE-47, 99, 153 and HBB were at least three orders of magnitude lower

516 than their corresponding oral reference doses (RfD) (Table A12).

517

518 Conclusions

519 To our knowledge, this is the first study reporting levels of PBDEs and NFRs in the air and dust

520 samples from the indoor and outdoor environments in Alexandria, Egypt. Results show that

521 PDBEs are present everywhere at elevated concentrations relative to NFRs targeted here. The

522 exposure assessment study indicated that inhalation of volatile flame retardants is a more

523 important exposure route for adults than dust ingestion. Accordingly, gaseous concentrations of

524 flame retardants should be included in future studies. For that purpose, LDPE could be used as

525 an effective indoor sampling technique in human exposure studies. Inclusion of the outdoor

526 samples indicated that: (i) indoor flame retardants are mainly emitted from the existing indoor

527 sources (higher concentrations in the indoor samples) and (ii) elevated fine dust samples are less

528 influenced by contamination from outdoor dust compared to the floor dust samples. Thus,

529 outdoor samples should be considered in future studies especially at locations lacking emission

530 inventory database. Concentrations of flame retardants in the elevated fine dust were higher than

531 those for the floor dust samples, which could result in underestimated exposures when relying on

532 floor dust. Nevertheless, estimated daily doses from all exposure routes for some of the target

533 analytes were much lower than available reference doses. However, the small number of floor 
dust samples analyzed in the current study is limiting conclusions. Our results could represent an important baseline database for developing response actions to limit the exposure to the organohalogenated flame retardants in the atmospheric environment of Alexandria, Egypt

\section{Supplementary data}

Details on the sampling, chemical and statistical analysis, estimation of gaseous concentrations and human exposure assessment are given in Appendix A.

\section{References}

Abbasi, G., Buser, A.M., Soehl, A., Murray, M.W., Diamond, M.L., 2015. Stocks and Flows of PBDEs in Products from Use to Waste in the U.S. and Canada from 1970 to 2020. Environ. Sci. Technol. 49, 1521-1528. https://doi.org/10.1021/es504007v

Abdallah, M.A.-E., Covaci, A., 2014. Organophosphate Flame Retardants in Indoor Dust from Egypt: Implications for Human Exposure. Environ. Sci. Technol. 48, 4782-4789. https://doi.org/10.1021/es501078s

Al-Omran, L.S., Harrad, S., 2016. Polybrominated diphenyl ethers and "novel" brominated flame retardants in floor and elevated surface house dust from Iraq: Implications for human exposure assessment. Emerg. Contam. 2, 7-13. https://doi.org/10.1016/j.emcon.2015.10.001

Ali, N., Ali, L., Mehdi, T., Dirtu, A.C., Al-Shammari, F., Neels, H., Covaci, A., 2013. Levels and profiles of organochlorines and flame retardants in car and house dust from Kuwait and Pakistan: Implication for human exposure via dust ingestion. Environ. Int. 55, 62-70. https://doi.org/10.1016/j.envint.2013.02.001

Ali, N., Dirtu, A.C., Eede, N. Van den, Goosey, E., Harrad, S., Neels, H., 't Mannetje, A., Coakley, J., Douwes, J., Covaci, A., 2012. Occurrence of alternative flame retardants in indoor dust from New Zealand: Indoor sources and human exposure assessment. Chemosphere 88, 1276-1282. https://doi.org/https://doi.org/10.1016/j.chemosphere.2012.03.100

Ali, N., Harrad, S., Goosey, E., Neels, H., Covaci, A., 2011. "Novel” brominated flame retardants in Belgian and UK indoor dust: Implications for human exposure. Chemosphere 83, 1360-1365. https://doi.org/10.1016/j.chemosphere.2011.02.078

Arinaitwe, K., Muir, D.C.G., Kiremire, B.T., Fellin, P., Li, H., Teixeira, C., 2014. Polybrominated Diphenyl Ethers and Alternative Flame Retardants in Air and Precipitation Samples from the Northern Lake Victoria Region, East Africa. Environ. Sci. Technol. 48, 1458-1466. https://doi.org/10.1021/es403600a

Bartkow, M.E., Hawker, D.W., Kennedy, K.E., Müller, J.F., 2004. Characterizing Uptake Kinetics of PAHs from the Air Using Polyethylene-Based Passive Air Samplers of Multiple Surface Area-to-Volume Ratios. Environ. Sci. Technol. 38, 2701-2706. https://doi.org/10.1021/es0348849 
Batterman, S.A., Chernyak, S., Jia, C., Godwin, C., Charles, S., 2009. Concentrations and Emissions of Polybrominated Diphenyl Ethers from U.S. Houses and Garages. Environ. Sci. Technol. 43, 2693-2700. https://doi.org/10.1021/es8029957

Björklund, J.A., Sellström, U., de Wit, C.A., Aune, M., Lignell, S., Darnerud, P.O., 2012. Comparisons of polybrominated diphenyl ether and hexabromocyclododecane concentrations in dust collected with two sampling methods and matched breast milk samples. Indoor Air 22, 279-288. https://doi.org/10.1111/j.1600-0668.2011.00765.x

Booij, K., Smedes, F., van Weerlee, E.M., 2002. Spiking of performance reference compounds in low density polyethylene and silicone passive water samplers. Chemosphere 46, $1157-$ 1161. https://doi.org/http://dx.doi.org/10.1016/S0045-6535(01)00200-4

Cao, Z., Xu, F., Covaci, A., Wu, M., Wang, H., Yu, G., Wang, B., Deng, S., Huang, J., Wang, X., 2014. Distribution Patterns of Brominated, Chlorinated, and Phosphorus Flame Retardants with Particle Size in Indoor and Outdoor Dust and Implications for Human Exposure. Environ. Sci. Technol. 48, 8839-8846. https://doi.org/10.1021/es501224b

Cequier, E., Ionas, A.C., Covaci, A., Marcé, R.M., Becher, G., Thomsen, C., 2014. Occurrence of a Broad Range of Legacy and Emerging Flame Retardants in Indoor Environments in Norway. Environ. Sci. Technol. 48, 6827-6835. https://doi.org/10.1021/es500516u Civan, M.Y., Kara, U.M., 2016. Risk assessment of PBDEs and PAHs in house dust in Kocaeli, Turkey: levels and sources. Environ. Sci. Pollut. Res. 23, 23369-23384. https://doi.org/10.1007/s11356-016-7512-5

de Wit, C.A., 2002. An overview of brominated flame retardants in the environment. Chemosphere 46, 583-624. https://doi.org/http://dx.doi.org/10.1016/S0045-6535(01)002259

Dickhut, R.M., Cincinelli, A., Cochran, M., Kylin, H., 2012. Aerosol-mediated transport and deposition of brominated diphenyl ethers to Antarctica. Environ. Sci. Technol. 46, 3135-40. https://doi.org/10.1021/es204375p

Dodson, R.E., Perovich, L.J., Covaci, A., Van den Eede, N., Ionas, A.C., Dirtu, A.C., Brody, J.G., Rudel, R.A., 2012. After the PBDE Phase-Out: A Broad Suite of Flame Retardants in Repeat House Dust Samples from California. Environ. Sci. Technol. 46, 13056-13066. https://doi.org/10.1021/es303879n

Fromme, H., Hilger, B., Kopp, E., Miserok, M., Völkel, W., 2014. Polybrominated diphenyl ethers (PBDEs), hexabromocyclododecane (HBCD) and "novel" brominated flame retardants in house dust in Germany. Environ. Int. 64, 61-68. https://doi.org/10.1016/j.envint.2013.11.017

Hassan, Y., Shoeib, T., 2015. Levels of polybrominated diphenyl ethers and novel flame retardants in microenvironment dust from Egypt: An assessment of human exposure. Sci. Total Environ. 505, 47-55. https://doi.org/10.1016/j.scitotenv.2014.09.080

Hoh, E., Zhu, Hites, R.A., 2005. Novel Flame Retardants, 1,2-Bis(2,4,6-tribromophenoxy)ethane and 2,3,4,5,6-Pentabromoethylbenzene, in United States' Environmental Samples. Environ. Sci. Technol. 39, 2472-2477. https://doi.org/10.1021/es048508f

Hong, W.-J., Jia, H., Ding, Y., Li, W.-L., Li, Y.-F., 2016. Polychlorinated biphenyls (PCBs) and halogenated flame retardants (HFRs) in multi-matrices from an electronic waste (e-waste) recycling site in Northern China. J. Mater. Cycles Waste Manag. https://doi.org/10.1007/s10163-016-0550-8

Kademoglou, K., Xu, F., Padilla-Sanchez, J.A., Haug, L.S., Covaci, A., Collins, C.D., 2017. Legacy and alternative flame retardants in Norwegian and UK indoor environment: 
Implications of human exposure via dust ingestion. Environ. Int. 102, 48-56. https://doi.org/10.1016/j.envint.2016.12.012

Kennedy, K.E., Hawker, D.W., Müller, J.F., Bartkow, M.E., Truss, R.W., 2007. A field comparison of ethylene vinyl acetate and low-density polyethylene thin films for equilibrium phase passive air sampling of polycyclic aromatic hydrocarbons. Atmos. Environ. 41, 5778-5787. https://doi.org/https://doi.org/10.1016/j.atmosenv.2007.02.033

Khairy, M.A., Lohmann, R., 2014. Field calibration of low density polyethylene passive samplers for gaseous POPs. Environ. Sci. Process. Impacts 16, 414-421.

Khairy, M.A., Lohmann, R., 2013. Feasibility of using low density polyethylene sheets to detect atmospheric organochlorine pesticides in Alexandria, Egypt. Environ. Pollut. 181, 151-158.

Kurt-Karakus, P.B., Alegria, H., Jantunen, L., Birgul, A., Topcu, A., Jones, K.C., Turgut, C., 2017. Polybrominated diphenyl ethers (PBDEs) and alternative flame retardants (NFRs) in indoor and outdoor air and indoor dust from Istanbul-Turkey: Levels and an assessment of human exposure. Atmos. Pollut. Res. 8, 801-815. https://doi.org/https://doi.org/10.1016/j.apr.2017.01.010

La Guardia, M.J., Hale, R.C., Harvey, E., 2006. Detailed Polybrominated Diphenyl Ether (PBDE) Congener Composition of the Widely Used Penta-, Octa-, and Deca-PBDE Technical Flame-retardant Mixtures. Environ. Sci. Technol. 40, 6247-6254. https://doi.org/10.1021/es060630m

Leonetti, C., Butt, C.M., Hoffman, K., Miranda, M.L., Stapleton, H.M., 2016. Concentrations of polybrominated diphenyl ethers (PBDEs) and 2,4,6-tribromophenol in human placental tissues. Environ. Int. 88, 23-29. https://doi.org/http://dx.doi.org/10.1016/j.envint.2015.12.002

Liagkouridis, I., Lazarov, B., Giovanoulis, G., Cousins, I.T., 2017. Mass transfer of an organophosphate flame retardant between product source and dust in direct contact. Emerg. Contam. 3, 115-120. https://doi.org/https://doi.org/10.1016/j.emcon.2017.09.002

Lin, Y., Qiu, X., Zhao, Y., Ma, J., Yang, Q., Zhu, T., 2013. Polybromobenzene Pollutants in the Atmosphere of North China: Levels, Distribution, and Sources. Environ. Sci. Technol. 47, 12761-12767. https://doi.org/10.1021/es403854d

Liu, L.-Y., Salamova, A., He, K., Hites, R.A., 2015. Analysis of polybrominated diphenyl ethers and emerging halogenated and organophosphate flame retardants in human hair and nails. J. Chromatogr. A 1406, 251-257. https://doi.org/http://dx.doi.org/10.1016/j.chroma.2015.06.003

Mahmood, A., Malik, R.N., Syed, J.H., Li, J., Zhang, G., 2015. Dietary exposure and screeninglevel risk assessment of polybrominated diphenyl ethers (PBDEs) and dechloran plus (DP) in wheat, rice, soil and air along two tributaries of the River Chenab, Pakistan. Chemosphere 118, 57-64. https://doi.org/http://dx.doi.org/10.1016/j.chemosphere.2014.05.071

McDonough, C.A., Puggioni, G., Helm, P.A., Muir, D., Lohmann, R., 2016. Spatial Distribution and Air-Water Exchange of Organic Flame Retardants in the Lower Great Lakes. Environ. Sci. Technol. 50, 9133-9141. https://doi.org/10.1021/acs.est.6b02496

Means, B., 1989. Risk-assessment guidance for Superfund. Volume 1. Human Health Evaluation Manual. Part A. Interim report (Final). United States.

Nakari, T., Huhtala, S., 2010. In vivo and in vitro toxicity of decabromodiphenyl ethane, a flame retardant. Environ. Toxicol. 25, 333-338. https://doi.org/10.1002/tox.20499

Newton, S., Sellstrom, U., de Wit, C.A., 2015. Emerging Flame Retardants, PBDEs, and 
HBCDDs in Indoor and Outdoor Media in Stockholm, Sweden. Environ. Sci. Technol. 49, 2912-2920. https://doi.org/10.1021/es505946e

Pozo, K., Harner, T., Lee, S.C., Wania, F., Muir, D.C.G., Jones, K.C., 2009. Seasonally Resolved Concentrations of Persistent Organic Pollutants in the Global Atmosphere from the First Year of the GAPS Study. Environ. Sci. Technol. 43, 796-803. https://doi.org/10.1021/es802106a

Sacks, V.P., Lohmann, R., 2011. Development and use of polyethylene passive samplers to detect triclosans and alkylphenols in an urban estuary. Environ. Sci. Technol. 45, 2270-7. https://doi.org/10.1021/es1040865

Salamova, A., Ma, Y., Venier, M., Hites, R.A., 2014. High Levels of Organophosphate Flame Retardants in the Great Lakes Atmosphere. Environ. Sci. Technol. Lett. 1, 8-14. https://doi.org/10.1021/ez400034n

Schreder, E.D., La Guardia, M.J., 2014. Flame Retardant Transfers from U.S. Households (Dust and Laundry Wastewater) to the Aquatic Environment. Environ. Sci. Technol. 48, 1157511583. https://doi.org/10.1021/es502227h

Shoeib, M., Harner, T., Webster, G.M., Sverko, E., Cheng, Y., 2012. Legacy and current-use flame retardants in house dust from Vancouver, Canada. Environ. Pollut. 169, 175-182. https://doi.org/10.1016/j.envpol.2012.01.043

Stapleton, H.M., Sjödin, A., Jones, R.S., Niehüser, S., Zhang, Y., Patterson, D.G., 2008. Serum Levels of Polybrominated Diphenyl Ethers (PBDEs) in Foam Recyclers and Carpet Installers Working in the United States. Environ. Sci. Technol. 42, 3453-3458. https://doi.org/10.1021/es7028813

Stuart, H., Ibarra, C., Abdallah, M.A.-E., Boon, R., Neels, H., Covaci, A., 2008. Concentrations of brominated flame retardants in dust from United Kingdom cars, homes, and offices: causes of variability and implications for human exposure. Environ. Int. 34, 1170-1175.

Sverko, E., Tomy, G.T., Reiner, E.J., Li, Y.-F., McCarry, B.E., Arnot, J.A., Law, R.J., Hites, R.A., 2011. Dechlorane Plus and Related Compounds in the Environment: A Review. Environ. Sci. Technol. 45, 5088-5098. https://doi.org/10.1021/es2003028

Thuresson, K., Bjorklund, J.A., de Wit, C.A., 2012. Tri-decabrominated diphenyl ethers and hexabromocyclododecane in indoor air and dust from Stockholm microenvironments 1: Levels and profiles. Sci. Total Environ. 414, 713-721. https://doi.org/10.1016/j.scitotenv.2011.11.016

Weschler, C.J., Nazaroff, W.W., 2010. SVOC partitioning between the gas phase and settled dust indoors. Atmos. Environ. 44, 3609-3620. https://doi.org/https://doi.org/10.1016/j.atmosenv.2010.06.029

Wilford, B.H., Harner, T., Zhu, J., Shoeib, M., Jones, K.C., 2004. Passive Sampling Survey of Polybrominated Diphenyl Ether Flame Retardants in Indoor and Outdoor Air in Ottawa, Canada: Implications for Sources and Exposure. Environ. Sci. Technol. 38, 5312-5318. https://doi.org/10.1021/es049260x

Yue, C., Li, L.Y., 2013. Filling the gap: Estimating physicochemical properties of the full array of polybrominated diphenyl ethers (PBDEs). Environ. Pollut. 180, 312-323. https://doi.org/http://dx.doi.org/10.1016/j.envpol.2013.05.029 